A Bibliometric Review of the Status and Emerging Research Trends in Construction Safety Management Technologies

Mariam Akinlolu*, Theo C. Haupt ${ }^{\mathrm{b}}$, David John Edwards ${ }^{\mathrm{c}}$ and Fredrick Simpeh $^{\mathrm{d}}$

e-mail *akinlolumariam@gmail.com 


\title{
A Bibliometric Review of the Current Status and Research Trends in Construction Health and Safety Management Technologies
}

\author{
Technologies such as virtual reality (VR), online databases, Geographic \\ Information Systems (GIS), Building Information Modelling (BIM), Unmanned \\ Aerial Vehicle (UAV), 4D Computer-Aided Design (4D CAD), wearable \\ robotics have been adopted to improve construction site health and safety. \\ However, little attempt has been made to map global research on construction \\ health and safety technologies. Therefore, this paper conducts a review of \\ technologies for construction health and safety management to reveal emerging \\ research trends. A bibliometric review adopting a two-step literature selection \\ method was conducted to compile relevant publications from the Scopus \\ database. In total, 240 related papers were examined. VOSviewer was used to \\ develop a co-occurrence network based on the bibliographic data obtained. The \\ analysis focused on co-authorship per country, country/ region distribution, the \\ number of publications annually, publication source and source and trend of \\ research topics. Findings revealed that emerging trends in construction health and \\ safety technologies research focused on project health and safety design and \\ planning, visualisation and image processing for construction projects, digital \\ technologies for project monitoring, information management and Internet of \\ Things, automation and robotic systems, health and safety and accident \\ prevention and structure evaluation.
}

Keywords: Bibliometric Review; Construction; Health; Safety; Digitalisation; Digital Technologies; VOSviewer

\section{Introduction}

Health and Safety on construction job sites has become a subject of primary concern across construction industries worldwide (Zolfagharian et al., 2014; Enshassi et al., 2019; Furci and Sunidijo, 2020). Globally, the construction industry is perceived to have one of the poorest occupational health and safety records (Hinze and Teizer, 2011). Construction work is known to be executed in hazardous, clumsy environments and under poor and unhealthy working conditions (Zhou et al., 2012; Zhou et al., 2013; 
Welch et al., 2015; Li and $\mathrm{Ng}, 2017$; Li, 2018). Despite stringent health and safety regulations, no significant decline in the number of construction accidents has been recorded (Azmy and Zain, 2016). Regardless of the countless efforts made by health and safety authorities and government agencies to improve health and safety standards on construction sites, workers' injuries and fatalities continue to occur. Defective equipment, dangerous work areas and unhealthy and unsafe working conditions are cited as common causes of construction site injuries and fatalities (Hinze and Teizer, 2011; Li, 2015).

With the emergence of novel technologies, various types of technologies such as Virtual Reality (VR), online databases, Geographic Information Systems (GIS), Building Information Modelling (BIM), Unmanned Aerial Vehicle (UAV), 4D Computer-Aided Design (4D CAD), robotics and automation, laser scanning, photogrammetry and sensor-based technologies which have been around for some time have proven to provide a lasting solution to the problem of construction health and safety to prevent workers' injuries, accidents and improve construction job site health and safety (Zhou et al., 2011; Zhou et al., 2013; Welch et al., 2015; Zhang et al., 2017; Dodge Data and Analytics, 2017; Aghimien et al., 2019; Bansal, 2020).

In recent times, the use of a wide range of technological innovations to enhance health and safety on job sites has been a fast-growing area and an interesting topic within the engineering and research disciplines. Several studies on technologies for construction health and safety have been conducted and published, integrating research efforts, and creating a foundation for the promotion of improved health and safety performance on construction sites. A systematic review of literature on technology applications for construction health and safety is important for major construction stakeholders to comprehend, share ground-breaking and cutting edge research findings 
and capture emerging trends that have potential to impact the construction health and safety effort in future (Zhou et al., 2013; Liang et al., 2018).

While numerous studies reviewing construction health and safety technologies have been conducted, most of the previous studies have limited research focus and performed an analysis utilising limited selection criteria and samples ( Zhou et al., 2012; Zhou et al., 2013; Guo et al., 2017; Zhang et al., 2017; Yang et al., 2018; Aleksandrova et al., 2019; Akram et al., 2019). For example, Zhou et al. (2012) conducted a comprehensive review of the adoption of digital interventions and technologies for construction safety and digital design. Although, Zhou et al. (2013); Guo et al. (2017) used science mapping tools to provide an overview of the evolution of research trends of innovative technologies for health and safety improvement in the construction industry the review was limited to 119 and 111 publications, respectively. Some reviews focused on specific digital technologies such as BIM, sensor-based and realtime technologies for construction health and safety management (Yang et al., 2018; Zhao and Liu, 2018; Akram et al., 2019; Aleksandrova et al., 2019).

This study conducts further research compared to other reviews by providing an integrated and comprehensive bibliometric analysis of published research on construction health and safety technologies using science mapping. A bibliometric review of technologies for construction health and safety was conducted, adopting multiple methods such as frequency analysis, co-authorship network and co-occurrence network of keywords.

The contributions of this study differ from previous reviews in the following ways, namely;

(a) it covered an extensive range of systematically selected literature to reflect the current research status on the subject; and 
(b) it adopted a comprehensive bibliometric approach to explore the intellectual evolution and future research trends of technologies for construction health and safety. This approach prevents the arbitrariness of literature reviews and provides objective conclusions and reduces the risk of introducing bias.

In summary, findings from the systematic review and the identification of knowledge gaps in the existing literature can potentially provide researchers and industry practitioners with a comprehensive insight into intellectual landscapes, potential research frontiers on technologies for construction health and safety.

\section{Literature Review}

\section{Technologies for Health and Safety Management in Construction}

Technologies for health and safety have been in existence since the use of hard hats and protective glasses but have only begun to receive attention in the construction industry in recent years (Hinze and Teizer, 2011; Welch et al., 2015). With the development of new technologies, their use continues to gain attention worldwide (Zhou et al., 2013). Numerous studies have identified the use of BIM, VR and AR, drones, GIS, automation and robotics, unmanned machinery, sensing and warning technologies, 4DCAD as effective technologies for accident prevention and healthy and safe project delivery (Zhou et al., 2012; Zhou et al., 2013; Teizer, 2015; Bansal, 2020).

Li and $\mathrm{Ng}$ (2017); Li (2018) considered the application of wearable robotics and industrial robots, such as an exoskeleton, robotic arms, and the Assist Suit AWN-03 as practical approaches to improve the health issues and safety conditions of workers on site. Robotic arms are composed of aluminium servo brackets with a similar look to actual human arms. They are made up of infrared sensors for radial distance and a USB camera, which captures angles and provides the arms with feedback on whether it can lift an object or not (Yusoff et al., 2012; Li and Ng, 2017). The Suit AWN-03 which 
senses the movements of workers provides support for their backs, shoulders and thighs (Kyodo, 2015). The FORTIS Exoskeleton is another wearable robotics tool that enhances the strength and endurance of the wearers ( $\mathrm{Li}$ and $\mathrm{Ng}, 2015$; Frane, 2016). The power-assisted exoskeletons are configured to transfer energy through the skeleton of the wearer. The unpowered exoskeletons provide a feeling of weightlessness, redistribute weight and improve the posture of the wearer when carrying heavy objects (Li and $\mathrm{Ng}, 2015$ ).

Ahsan et al. (2007) and Zhang et al. (2017) argued that sensor-based technologies including sensor-based location, vision-based sensing and wireless sensor networks provide innovative methods for the advancement of real-time construction health and safety. As a viable technique, the application of wireless sensor networks used for forecasting and environmental monitoring could assist in the avoidance of accidents and improve construction site health and safety performance (Yusoff et al., 2012).

In construction health and safety applications, RFID technology has been used for some time to demonstrate real-time data gathering (Yin et al., 2009; Lo and Lin, 2013). RFID tags have been used in simulated construction environments to track the movement of workers, equipment, and materials. The resulting tag data is examined to determine if a near-miss incident has occurred (Zhou et al.,2013). This information can further be used to prevent future occurrences of these (ibid).

Virtual and Augmented Reality (VR and AR) create a computer-generated experience or imagery to simulate real-life scenarios. Augmented reality enhances reality by using technology to do so (Patrucco et al., 2010). Health and safety managers use both technologies to review safety tie-off points and create a genuine health and safety work experience through virtual drills, instructions, and health and safety 
scenarios viable for construction health and safety training (Li and Leung, 2017; Zhang et al., 2017).

To address the health and safety issues arising from the complex nature of construction projects, Suermann (2009); Eastman et al. (2011); and Zhou, et al. (2013) indicated that BIM could be applied efficiently for the planning and management of health and safety on construction sites. A result of incorporating BIM in construction activities is developing health and safety-training videos for workers (Azhar et al., 2012). Using the 3-D BIM model to conduct visual health and safety training enables site workers to develop a better understanding of the actual site conditions and working environment (Watson, 2010; Ganah and John, 2015; Druley et al., 2016).

\section{Research Methods}

Pritchard (1969) introduced the concept of bibliometric review and analysis and argued that through quantitative analysis of patterns and boundaries, it has the potential to provide insights into research in a specific field. The bibliometric analysis utilises science mapping tools for visualising physical aspects of scientific research and domains and describing the structure of their disciplines (Van Eck and Waltman, 2010; Akram et al., 2019). It is the mathematical analyses of publications and their properties such as, for example, authorship, publication source, type, and timelines (de Rezende et al., 2018). This study adopted this approach to categorise and examine research on digital technologies for health and safety on construction sites, which would arguably assist researchers in establishing future research directions. Science mapping was used in the bibliometric analysis to visualise and describe the physical aspects and structure of the scientific domain. Bibliometric analysis has already been applied in several domains such as Building Information Modelling (BIM) (He et al., 2017; Zhao et al., 
2017; Olawumi et al., 2017; Lu et al., 2017), sustainability ( Olawunmi and Chan, 2018), green building (Albort-Morant et al., 2017; Wuni et al., 2019; Darko et al., 2019), Public-Private Partnership (PPP) (Song et al., 2016; Neto et al., 2016).

The research design for the bibliometric analysis in this study is presented in Figure 1.

The following bibliometric techniques were adopted, namely:

i) Frequency analysis to analyse and examine publications by publication type and source, country/region distribution and number publications annually.

ii) Co-authorship analysis includes a co-occurrence and collaborative network of authors in the indexed corpus of documents.

iii) Co-occurrence of keywords analysis identifies the occurrence of correlated keywords or terms in digital technologies for construction health and safety literature, analyses the concentration by global research over periods, and tracks the evolution of trends.

\section{Literature search and indexing strategy}

The Scopus database was selected as a data source because of its comprehensiveness and wide coverage (Hong et al., 2012; Hosseini et al., 2018). Scopus is considered as a major scientific research database and regarded as a rapidlygrowing database in terms of providing researchers with information on the most prominent academic literature in any particular scientific domain (Chadegani et al.,2013; Olawunmi et al., 2017).

An online retrieval was conducted, and 3,189 data records were obtained. A keyword search was conducted to retrieve all related publications from the Scopus database. The specific keywords used were "Safety" AND Health" AND“Digital Technologies" AND "Construction". The literature selection focused on published 
construction industry-related journal articles and conference proceedings. Zheng et al. (2016) Vuksic et al. (2018) argued that journals and conference papers are considered more reliable sources in a literature review and generally provide more detailed information when compared to other sources. A two-step screening was conducted to filter relevant publications from the retrieval results based on the types of publication type and other criteria.

In the first selection stage book reviews, book chapters, letters, and editorial materials were excluded from the data set. After this filtration, a total of 3,133 relevant publications were used for the second stage of literature selection. A preliminary review was further conducted by reviewing the titles, abstracts, and keywords of the 3,133 publications. For a further selection and elimination of irrelevant articles, four filter criteria were applied to select publications that aligned with the research topic and theme. The filter criteria used were:

(1) Articles that did not feature studies conducted in the engineering industry and were not construction related. For instance, the article by Cui and Wang (2013) was excluded, which explored real-time monitoring technology of material transportation to dams and its application in core rockfill dams.

(2) Articles that did not feature studies written in the English language on construction health and safety. For example, the article by Fan et al. (2019) was excluded, which explored the application of key technologies for the intelligent construction of Jinsha River hydropower projects. The study was published in the Chinese language.

(3) Articles that did not feature construction health and safety-related studies conducted from 2009 to 2019. For instance, the article by Maas and Van Gassel 
(2005) was excluded, which examined the influence of robotics and automation on construction health and safety performance as it fell outside the selected window.

(4) Articles that focused on other aspects of construction but did not directly address issues of construction health and safety. For example, the article by Papayianni and Pachta (2016) was excluded, which explored the evolution of building materials and philosophy in the construction industry.

After filtration using these criteria, a total of 240 bibliographic data records remained, which included 84 journal articles (35\%) and 156 conference papers (65\%). Figure 2 presents a detailed outline of the literature search and indexing approach used in this study.

\section{Selection of Tools for Analysis}

Tools such as CiteSpace, HiteSpace, VOSviewer, Gephi and BibExcel can be used for visualisation (Cobo, López-Herrera et al., 2011). In this study, the VOSviewer software was used to analyse statistical evidence obtained from the data source and develop a cooccurrence map. VOSviewer has gained widespread usage in the review of construction literature and has been adopted in previous construction health and safety research (Zhou et al., 2013; Guo et al., 2017; Zhang et al., 2018; Liang et al., 2018; Jin et al., 2019; Akram et al., 2019; (Aghimien et al., 2019; Vigneshkumar and Salve,2020).

VOSviewer is a software tool used for the construction and visualisation of graphical and bibliometric maps. The software offers the functionality required to display large bibliometric networks in an easily interpretable way (Van Eck and Waltman, 2014). Compared to many of the other visualisation tools, the VOSviewer software is user friendly, freely available, and contains special features such as network mapping and normalisation (Van Eck and Waltman, 2014). As a result, VOSviewer developed a co-occurrence map based on the bibliographic obtained from the Scopus 
database.

Labels and circles present items in the visualization network. Therefore, the distance between each item in the visualisation network approximately indicates the relatedness of the items (Van Eck and Waltman, 2017). In general, the closer two items are to each other, the stronger their relatedness. Items in the network are connected with lines that represent links. In the cluster network, the smart local moving algorithm and the colour of an item are determined by the cluster to which the items belong.

\section{Results of Data Analysis}

\section{Annual Publication Distribution}

The number of publications per year from 2009 to 2019 is presented in Figure 3. Before 2013, the number of relevant papers published each year was not more than 17 papers. A significant increase is evident in 2012 with 10 publications more than the previous year. In 2013, 34 publications were recorded with 6 publications more than in 2012. There was a decline in the number of publications in 2015, recording 14 fewer publications than 2013 and 1 publication less than 2014. The number of publications for subsequent years remained constant with the number of publications recorded for 2016, 2017 and 2018 being 21, 22 and 22, respectively. In 2019 recorded 12 publications to date were published. Previous studies have opined that with 4IR gaining more attention in recent years, there will be an increase in research concentrated on digitalisation and use of advanced technologies for construction health and safety (Zhou et al., 2013; Oesterreich and Teuteberg, 2016; Guo et al., 2017; Vuksic et al., 2018).

\section{Publication type and source analysis}

As shown in Figure 4, a total of 240 documents were published, which includes 84 journal articles and 156 conference papers. The lower number of journal articles 
could be due to the more thorough peer-review process that journal articles have to undergo before publication resulting in a reduction in immediacy compared to conferences papers which are published more quickly and in larger volumes depending on the relevance of the conference theme.

Table 1 presents the 10 most cited publications sources alongside the number of citations and documents cited. The citations and number of documents were obtained from the VOSviewer analytical function set at a minimum of two publications per source. Automation in Construction and IEE Transactions in Industrial Electronics were found to be the most cited publication sources with 446 and 96 citations, respectively.

\section{Country/Region Distribution}

Figure 5 shows the distribution of publications across countries or regions in the world. The institutional address or affiliation of the corresponding author was used to calculate the publication distribution across countries. Countries were identified alongside the number of citations and documents cited. The citations and number of documents were obtained from the VOSviewer analytical function set at a minimum of 2 publications per country. China was found to have the highest number of publications with a total of 72 documents and 95 citations. This is followed by the United States of America (59 publications, 503 citations), United Kingdom (14 publications, 591 citations), France ( 11 publications, 62 citations), Germany (9 publications, 336 citations), Canada (9 publications,53 citations), Brazil (5 publications, 31 citations), Austria (4 publications, 35 citations), Spain (2 publications, 25 citations) and Israel (2 publications, 94 citations).

As shown in Figure 5, 10 countries or regions from four continents were identified except for Africa, Australia, and Antarctica. This finding affirms those of Zhou et al. (2013); Guo et al. (2017); Vuksic et al. (2018); Aghimien et al. (2019); 
Akram et al. (2019) which revealed that there is greater research focus on the application of digital technologies for construction health and safety in Europe, Asia and the Americas compared to other continents, as countries from these continents have been ranked the most digitally innovative countries in the world (Martínez-Aires et al., 2018; Institute of Management Development, 2018). This finding further indicates that discussions on digitalisation are slow-paced in Africa and are only in the very early stages, indicating that considerable efforts and awareness should be made to foster the adoption of innovative technologies for the management of construction health and

safety in Africa. Arguably, this trend is not surprising given the historical enormity of other pressing issues demanding attention on the continent than a practical focus on technological advances and innovations which typically demand high levels of investment, scarce resources, and limited skills.

\section{Visualisation}

Results of the visualisation of the 240 documents retrieved from the Scopus database and VOSviewer are highlighted in the following section.

\section{Publication per author and Co-Authorship Network}

A co-authorship network was generated using VOSviewer to identify the network of authors that had undertaken collaborative research on digital technologies for construction health and safety management. The 91 documents assessed had a total of 744 authors, including the lead and co-authors. With the VOSviewer analytical function set at a minimum of two documents per author and 1 citation per author, 27 authors met the threshold. Table 2 presents a list of authors with the most documents and citations in this research domain. These are the core authors who have made 
significant contributions to research on technologies in construction health and safety management and are well cited. An analysis of the most productive authors revealed that Yang, L. (3 documents, 12 citations), Zhang, W. (3 documents, 12 citations), Lucia, O. (2 documents, 18 citations) and Zhang, P. (2 documents, 10 citations) were the authors with the most productive in this domain. Although Li, H. and Zhang, L. have produced 4 documents, these documents have only been cited 2 and 8 times, respectively.

Figure 6 shows the overlay visualisation network with a total of 30 links and 31 total link strength. The total strength of the co-authorship links is the strength of the links of an author with other authors (Van Eck and Waltman, 2010).

The overlay visualisation network is presented to reflect the author links, the pattern of collaboration, the average year of publication of the authors and their clusters. There were ten clusters of co-authorships. The cluster around Wang, Y., Yang, L., Yang, F., Sun, Y., Yang, Y., Zhang P. is noteworthy and indicates strong -authorship links and collaborative research among them. Li, W., Li, Z., Liu, W. and Pincu, R. labelled in blue colour were the earliest set of authors to publish documents in the research area. Authors in the yellow cluster such as Li, Y., Li, J, Zeng, J., and Yu, Z. are the authors with the most recent publications from 2016 to date.

\section{Co-occurring Keywords Analysis}

Keywords are significant words which serve as a point of reference and aid the description of contents and understanding of concepts in research articles ( $\mathrm{Su}$ and Lee, 2010; Olawunmi and Chan, 2018). Numerous topics and themes have evolved in research concentrated on the application of digital technologies for construction health and safety in the last decade. Data from the Scopus database was imported to VOSviewer to generate a visualisation map for co-occurring keywords and an 
overlaying network of research topics on technologies for construction health and safety. The proximity of keywords to one another and the similarity of keywords determines the degree of co-occurrence (Van Eck and Waltman, 2014; Liang et al., 2018).

Keyword Clusters and Keyword trends

A keyword co-occurrence analysis was conducted to determine the fundamental structure and clusters in digital technologies for construction health and safety research. A co-occurrence network was derived from a total of 2,970 keywords using the VOSviewer software. With a minimum number of 5 co-occurrence of keywords, 52 keywords co-occurred and 7 significant keyword clusters were identified. Figure 7 presents a network visualisation map of the 7 co-occurring keyword clusters with 338 links and a total link strength of 512. Table 4 shows the most active keywords in the 240 analysed documents.

(1) Cluster 1 - Project Safety Design and Planning: labelled in red on the map had 13 members with keywords such as architectural design, computer-aided design, digital avionics, digital technologies, BIM, human-computer interaction, laws and legislations, real-time systems, research, the security of data, construction projects and virtual reality. This cluster was further summarised as 'Project Health and Safety Design and Planning (PHSDP)'.

Health and safety planning and design is a major component of the health and safety management system. Due to the complex nature of construction sites, traditional health and safety planning have proven to be time-consuming and errorprone (Melzner et al., 2013; Toh, Goh and Guo, 2016; Guo et al., 2017; Khazandi et al., 2020). 
Recently, there has been a significant increase in the use of digital technologies to improve construction health and safety through health and safety planning and design, as many studies are researching this area. The role of technologies for visual assessment of construction site and identify potential hazards have been identified by (Watson, 2010; Azhar et al., 2012). Watson (2010); Ku and Mills (2010); Kim and Ahn (2011); Ganah and John (2015); Zhang et al. (2013); Zhang et al., (2015) explored the use of digital technologies such as BIM, VR and AR in the design and operation stages to represent and manage graphics as well as automatically analyse designs, identify health and safety-related design deficiencies, generate illustrations, reports, design schedules and for simulation of construction processes.

(2) Cluster 2 - Visualisation and Image Processing for Construction Projects: represented in the green region of the map had 9 items with keywords such as augmented reality, cameras, data handling, image processing, life cycle, maintenance, photogrammetry, reliability and 3D. Keywords in this cluster can be associated with 'Visualisation and Image Processing for Construction Projects (VIPCP)'.

Increasing efforts have been made in recent years, especially after 2010 to apply visualisation technologies for location and proximity warning in construction sites (Patrucco et al., 2010; Teizer et al., 2010; Carbonari et al., 2011). Kang and Wang (2013) assess the use of visualisation and image processing technologies by highlighting the application of AR for construction health and safety through the projection of 3D imagery on the physical surroundings of workers as they walk through construction sites with mobile devices or special helmets and using GPS and cameras to present real-time data geospatially giving updated user feedback. 
The role of visualisation and image processing technologies for situational awareness has also been highlighted in numerous studies (Teizer et al., 2010; Cheng and Teizer, 2012; Zhou et al., 2013; Luo et al., 2016).

(3) Cluster 3 - Digital technologies for Project Monitoring: labelled in blue had 9 members with keywords such as computer simulation, decision making, digital instruments, information technology, monitoring, sensors, technology, virtual instrument, and virtual instrument technology. This cluster was summarised as 'Digital technologies for Project Monitoring (DTPM)'.

The application of technologies such as sensors and VR for real-time monitoring of buildings or building components is evident in past literature and have made a significant breakthrough (Zhang et al., 2017; Guo et al., 2017). Zhang et al. (2017) found that visual inspection methods employed to monitor bridge construction projects do not provide detailed and reliable information. New technologies such as wireless radio transmitters have been developed to monitor and inspect bridge construction projects.

In project monitoring, sensors have been applied to prevent accidents and prevent worker - equipment collisions by monitoring the entire environment on construction sites (Ni et al., 2012; Sung et al., 2016; Guo et al., 2017; Zhang et al., 2017). Wireless sensor networks have been found to enhance and facilitate information flow among design teams on construction sites as well as ease the circulation of a network on construction site (Zhang et al., 2013; Luo et al., 2013; Sung et al., 2016). Zhong et al. (2014) adopted sensors to monitor tower crane collisions on construction sites. The data obtained was transmitted through a wireless network to a remote monitoring platform and analysed in the terminal 
located in the operation room of the river to ensure the health and safety of crane towers.

(4) Cluster 4 - Information Management and Internet of Things: represented in yellow had 7 items with keywords such as digital storage, hazards, information management, internet, internet of things, remote control, and health and safety engineering. This cluster can be seen to contain keywords relating to "Information Management and Internet of Things (IMIoT).

IoT has recently become an enormous innovation and trend in the history of technological advancement (Haupt et al., 2019). The network comprises the interaction of embedded tools and devices accessed and connected to the internet through wired and wireless networks (Dodge Data and Analytics, 2017). Kim et al. (2014) studied the applications of information technology in construction health and safety management.

Information technology and IoT technologies have been used to improve several aspects of construction health and safety such as health and safety training and education, risk identification, health and safety monitoring and evaluation and health and safety inspections (Zhou et al., 2012; Dodge Data and Analytics, 2017). IoT monitoring technologies are adapted to monitor site activities that require constant close attention (Dodge Data and Analytics, 2017). Applications are designed to enhance decision-making processes by transmitting real-time responses among workers (Jing et al., 2014). For smart construction health and safety, information is collected with the use of sensors and gateways, and clouds are then used to wirelessly store, analyse and review the data collected (Hopah and Vayvay, 2018). Yu (2009) designed a prototype web tool to assist in the evaluation of potential designers, contractors, and coordinators. The online system applies 
Artificial Intelligence during the evaluation process to support decision making through risk identification and assessment, and information capture and analysis. Project performance is monitored over a specified period by analysing scores assigned to certain parameters (Yu, 2009). Azmy and Zain (2016) identified the development of a real-time communication system for monitoring construction health and safety on diverse projects. A centralised database is used to store transmitted data and is analysed by site managers to inform decisions on construction sites (Teizer, 2015). This system is an alternative platform for sourcing construction health and safety reports and statistics.

(5) Cluster 5 - Automation and Robotic Systems: labelled in purple had 9 members with keywords such as automation, computer software, robotics, kinematics digital control systems, digital devices, robots, electronic power systems and standards. This cluster was summarised as 'Automation and Robotic Systems (ARS)'.

Adopting robotic systems is a current trend for accelerating and automating construction tasks (Chu, 2013; Bock et al., 2012). Numerous studies have considered robotics and automation to have the potential to solve health and safety issues in construction (Chu, 2013; Frane, 2016; Li, 2018). Kim and Cho (2010); Teizer (2015) argued that automation is a significant alternative that can enhance up-to-date gathering of construction health and safety data and improving the construction environment to ensure better overall health and safety performance.

Several types of robotic systems have been developed to improve the quality of construction projects, productivity, health issues of workers as well as other safety problems (Ruggiero et al., 2016). Controlled by computers on-site and dependent on advanced detection and control, robots are employed in the autonomous installation and gathering of heavy construction materials, which 
usually require enormous labour, and to construct structures such as skyscraper towers (Jung et al., 2013; Niu et al., 2017; Li and Leung, 2018).

Yu (2009) discovered an automated machine called "Blockbot" which is utilised on-site to erect straight bonded brick walls accurately. Azmy and Zain (2016) assessed a model for automation in monitoring and managing fall hazards in scheduled building construction projects. This model determines high-risk areas in construction activities and gives a graphical presentation on the drawings of a project. Balaguer and Abderrahim (2018) proposed the use of ROMA climbing robots for inspection of steel-based infrastructures in construction. This robotic system is a self-supporting locomotion system that conducts inspections in $3 \mathrm{D}$ complex environments and operates similarly to a caterpillar. Vatsal and Hoffman (2017) assessed the use of elbow-mounted robotic arms to enhance workers comfort and safety through stabilisation and bracing; reaching and transfers; and reducing effort in repetitive activities.

(6) Cluster 6 - Health and Safety and Accident Prevention: represented in green had 7 items showing keywords such as accident prevention, digital radiography, nondestructive examination, risk assessment, health and safety, RFID, and safety testing. This cluster was grouped as 'Safety and Health and Accident Prevention (SHAP)'.

Due to the high rate of injuries, accidents and fatalities in the construction industry, researchers have explored the application and benefits of technologies to prevent accidents on construction sites (Hwang and Liu, 2011; Wang and Razavi, 2016; Zhang et al., 2017). Chae (2009) designed a Collision Accident Prevention Device (CAPS) that uses RFID technology to estimate the size of the working area. The device supports accident prevention involving vehicles, 
heavy equipment and workers using data from the working area of each object. CAPS estimate and calculates the positional relation of heavy equipment and workers and once determined that a worker is in the restricted area of heavy equipment, a message warning message is sent to the worker and concerned parties. Wu et al. (2010) highlighted the application of wireless networks based on RFID for automatic risk identification and construction accidents prevention. Similarly, Soungho and Tomohiro (2010) applied a system based on active RFID tags to manage and validate the safety of excavators through field tests.

(7) Cluster 7 -Structure Evaluation: was the last cluster, represented in orange and had 3 members with keywords such as cracks, image analysis and strain measurement. This cluster was summarised as 'Structure Evaluation (SE). In recent years, technologies such as temperature sensors, pressure sensors and optical fibre sensors have been adopted to evaluate structures and structural components (Tang and Yan, 2013; Yu et al., 2015; Sekiya et al., 2016).

Monitoring stress, temperature and deformation is a proper way to acquire data on the safety condition of structures (Zhang et al., 2017). Therefore, the evaluation of structures is an important aspect of health and safety management in construction. Temperature sensors have been applied to construction for concrete shrinkage and crack monitoring (Zhang et al., 2013), concrete curing (Luo et al., 2013), and to monitor the temperature of structural components (Ding et al., 2014).

Lee et al. (2014) applied temperature sensors installed in concrete to record the hardening process of concrete to evaluate the compressive strength and quality of the concrete. Bremer et al. (2017) applied optical fibre sensors to monitor and evaluate cracks and strains in structures. 
Figure 8 presents an overlay visualisation network generated from VOSviewer, showing the evolution of research topics in terms of co-occurring keywords over ten years (20102019). With a co-occurrence of 5 keywords, it is evident that starting from 2012, and there was a growing trend of research on topics related to virtual instruments, digital instruments, computer simulation and sensors.

From the generated network and links, it is evident that in 2013 there was an increase in publications on topics such as digital avionics, cameras, design, hazards, and digital control systems. This finding implies that during 2013 numerous studies focused on the use of digital avionics systems such as drones and the design of digital control systems for construction safety hazards. In 2014, keywords with strong co-occurrences were identified as reliability, monitoring, safety testing, automation, image processing, information technology and remote control. This indicates that in 2014, research on digitalisation concentrated on the use of automation and information technology for construction site health and safety and health and safety monitoring. In 2015, researchers focused on robotics and automation for accident prevention and intensified issues of health and safety engineering and risk assessment. Keywords included digital storage, safety engineering, accident prevention, risk assessment, human-computer interaction and digital devices. From 2016 keywords such as architectural design, life cycle, image analysis, cracks, strain measurement, law and legislation and decision making were found to co-occur. In this last period, innovative design and sustainable concepts for the evaluation and analysis of structures received more attention from researchers. It is also evident that studies in this period intensified on decision making and the prevailing health and safety legislative and regulatory frameworks in the construction industry. 
Findings from this study indicate that research on digital technologies for construction health and safety has evolved from the incorporation of digitalisation of construction health and safety through the application of digital control systems, information technology, robotics and automation and digital design. Subsequent research has concentrated on decision-making processes on the application of digital technologies for construction health and safety and the development of laws and legislations that promote and support digitalisation for construction health and safety. Therefore, it can be deduced that as technological innovations for construction health and safety evolve, the research focus will be influenced.

\section{Agenda for future research on construction health and safety management technologies}

Given the recent global challenges presented by the COVID-19 pandemic which resulted in the almost universal cessation of construction activities in many countries, the opportunity is presented to expand research into technologies which will prevent the exposure of all stakeholders in the industry to potential infection of not only the current COVID-19 but also increase the preparedness of the construction industry which by its very nature is still labour-intensive for any future pandemic or global disaster.

The efficacy of social distancing between workers on site of around $2 \mathrm{~m}$, places challenges in the way construction activities are traditionally executed. Future research will focus more on examining core construction functions and developing technologies that can execute them either without the physical involvement of construction workers themselves or involvement from a distance from other workers. Further, pre-site entry screening and detection technologies will have to be developed as early warning mechanisms to prevent possible infection at the point of entry to construction sites. Protocols to promote off-site and working from remote locations while still monitoring 
work activities and project progress will need attention. Issues of cybersecurity will need extra attention when using virtual communication platforms. The further development of automated operatorless plant and equipment will need to be accelerated. Innovative logistical management of the supply chain and material delivery to the site will also have to be investigated and improved under the conditions of the 'new norm.' Legislative and regulatory frameworks that govern construction will have to be adapted to suit new contractual, working and labour employment conditions that include provisions for the use of new technologies, training to use these as well as revisiting definitions of force majeur.

The agenda for future research is endless, given the vast amount of opportunities to improve overall health and safety performance using innovative and advanced technologies at worker, project, sector, national and global levels.

\section{Conclusion}

Globally, the concept of digitalisation and technology for construction health and safety has received wide attention. It has been found that the application of digital technologies has significantly increased the effectiveness of health and safety management on construction sites. The study presented a bibliometric review of technologies for construction health and safety by conducting a comprehensive bibliometric review of 240 relevant publications from the Scopus database. A frequency and co-occurrence analysis were conducted to identify publication trend in terms coauthorship per country, country or region distribution, the number of publications annually, publication source and type. The study presented the evolution of research topics through a cluster of existing topics, providing researchers with a trend of existing literature directions to guide future research on construction health and safety technologies. Publication trends over the past decade and the distribution of 
publications across different countries and regions were identified. The United Kingdom, USA and China are the three leading countries in construction health and safety technologies research in terms of publications, citation, collaboration, and coauthorship network. Automation in Construction and IEE Transaction on Industrial Electronics were found to be the most cited publication sources. The co-occurrence of keywords analysis identified 7 main research topics evolving from research on construction health and safety technologies from 2009 to 2019. Consequently, 5 emerging trends were identified.

It is evident from the study that research on the implementation of digital technologies for construction health and safety in Africa is under-represented in literature compared to other continents suggesting that research is embryonic at best. The study identified possible areas for future research in the African context. Since the Scopus database was used as the data source for the study and only considered documents written in English, the study recommends that further studies be conducted using a combination of databases and documents published in other languages.

\section{References}

Aghimien, D., Aigbavboa, C., Oke, A. and Thwala, W.2019. Mapping out research focus for robotics and automation research in ssconstruction-related studies: A bibliometric approach, Journal of Engineering Design and Technology, aheadof-print.

Ahsan, S., El-Hamalawi, A., Bouchlaghem, D., Ahmad, S. 2007. Mobile Technologies for Improved Collaboration on Construction Sites, Architectural Engineering and Design Management, 3:257-272.

Akrama, R., Thaheemb, M.J., Nasira, A. R., Alic, T.H., Khana, S. 2019. Exploring the role of building information modeling in construction safety through science mapping, Safety Science, 120: $456-470$. 
Albort-Morant, G., Henseler, J., Leal-Millan, A., Cepeda-Carrion, G., 2017. Mapping the

Field: A Bibliometric Analysis of Green Innovation. Sustainability 9.

Aleksandrova Elena \& Vinogradova Victoria \& Tokunova Galina, 2019. Integration of digital technologies in the field of construction in the Russian Federation, Engineering Management in Production and Services, Sciendo, $11(3): 38-47$.

Azhar, S., Bahringer, A., Khalfan, M., Sattineni, A., Maqsood,T. 2012. BIM for Facilitating Construction Safety Planning and Management at Jobsite, Proceeding of the CIB W099 International Conference on Modelling and Building Health and Safety, 82 -92.

Azmy, N, Zain, A. 2016.The Applications of Technology in Enhancing Safety and Health Aspects on Malaysian Construction Projects, ARPN Journal of Engineering and Applied Sciences, $11: 7209-7213$.

Balaguer, C., Abderrahim, M. 2008. Trends in Robotics and Automation in Construction, Robotics and Automation in Construction, Intechopen.

Bansal, V.K. 2020. Use of GIS to consider spatial aspects in construction planning process, International Journal of Construction Management, 20 (3): 207-222.

Bock, T., Linner, T., Ikeda, W. 2012. Exoskeleton and Humanoid Robotic Technology in Construction and Built Environment, The Future of Humanoid Robots Research and Applications, Intechopen.

Bremer, K.Weigand, F. and Zheng, Y.L. 2017. Structural Health Monitoring Using Textile Reinforcement Structures with Integrated Optical Fiber Sensors. Sensors, 17: 345 .

Carbonari, A., Giretti, A., Naticchia, B., 2011. A proactive system for real-time safety management in construction sites. Automation in Construction 20:686-698.

Chae,S. 2009. Development of Warning System for Preventing Collision Accident on Construction Site, 26th International Symposium on Automation and Robotics in Construction.

Chadegani, D.A.A., Salehi, H., Yunus, M.M., Farhadi, H., Fooladi, M., Farhadi, M. and Ebrahim, N.A. 2013. A comparison between two main academic literature collections: web of science and scopus, Asian Social Science, 5: 18-26. 
Cheng, T., Teizer, J., 2012. Modelling tower crane operator visibility to minimize the risk of limited situational awareness. Journal of Computing in Civil Engineering $28,04014004$.

Cheung, S.O, Cheung, K.K.W, Seun, H.C.H. 2004. CSHM: Web-based safety and health monitoring system for construction management, Journal of Safety Research, 35(2):159-170.

Chu, B. 2013. Robot-based construction automation: an application to steel beam assembly, Autom. Constr. 32: 46-61.

Cobo, M.J., López-Herrera, A.G., Herrera-Viedma, E., Herrera, F., 2011. Science mapping software tools: review, analysis, and cooperative study among tools. J. Assoc. Inform. Sci. Technol. 62 (7): 1382-1402.

Cui, B. and Wang, R. 2013.Real-Time Monitoring Technology of Material Transportation to Dam and Its Application in Core Rockfill Dam, Second International Conference on Transportation Information and Safety.

Darko, A., Zhang, C., Chan, A.P.C., 2017. Drivers for green building: A review of empirical studies. Habitat International 60: 34-49.

de Rezende, L.B., Blackwell, P., Gonçalves, M.D.P., 2018. Research focuses, trends, and

major findings on project complexity: a bibliometric network analysis of 50 years of project complexity research. Project Manage. J. 49 (1): 42-56.

Ding, N., Hu, C.L. and Yu, J.C. 2014. Application of distributed fiber-optic temperature sensor in shaft-sinking by freezing in coal mine. Transducer Microsyst. Technol., 33:154-156.

Dodge Data and Analytics 2017. Safety Management in the Construction Industry, Smart Market Report, Bedford, MA.

Druley, K., Musick, T., Trotto, S. 2016. Researcher explores how to make temporary structures on construction site safe, Safety and Heath, 193.

Eastman, C., Teicholz, P., Sacks, R., Liston, K. 2011. BIM Handbook: A Guide to Building Information Modeling for Owners, Managers, Designers, Engineers and Contractors, 2nd ed. John Wiley and Sons, NY.

Enshassi, A., Ayyash, A., Choudhry, R. M. 2016. BIM for construction safety improvement in Gaza strip: awareness, applications and barriers. International Journal of Construction Management, 16(3): 249-265. 
Enshassi, A.,Saleh, N., Mohamed, S. 2019. Barriers to the application of lean construction techniques concerning safety improvement in construction projects, International Journal of Construction Management.

Fan, Q., Lu,Y., Zhou,S., Yang,N.,Lin,E.,Li,G. 2019. Research and practice on intelligent construction technology system of Jinsha River hydropower projects, Shuili Xuebao/Journal of Hydraulic Engineering,50(3):294-304.

Furci, J., Sunindijo, R. 2020. Impacts of the WHS Act 2011 on safety management in small and medium construction companies, International Journal of Construction Management, 20(3):196-206.

Ganah, A., John, G.A. 2015. Integrating building information modelling and health and safety for onsite construction, Safety and Health at Work, 6: 39-45.

Guo, H.L.; Yu, Y.T.; Skitmore, M. 2017. Visualization technology-based construction safety management: A review. Automat. Constr., 73: 135-144.

Guo, B., Scheepbouwer, E., Yiu, K. T., Gonzalez, V. 2017. Overview and analysis of digital technologies for construction safety, Proceedings of the 41st AUBEA, 35 July 2017; Melbourne, Australia.

Haupt, T.C., Akinlolu, M. and Raliile, M.T., 2019. Applications of digital technologies for health and safety management in construction. In: Sandanayake, Y.G., Gunatilake, S. and Waidyasekara, A. (eds). Proceedings of the 8th World Construction Symposium, Colombo, Sri Lanka, 8-10 November, 88-97.

He, Q.,Wang, G., Luo, L., Shi, Q., Xie, J. and Meng, X. 2017.Mapping the managerial areas of Building Information Modeling (BIM) using scientometric analysis. Int. J. Proj. Manag., 35: 670-685

Hinze, J., Teizer, J. 2011. Visibility-related fatalities related to construction equipment, Safety Science, 49:709-718.

Hopah, E. and Vayvay, O. (2018). Internet of Things (IoT) and its challenges for usability in developing countries, International Journal of Innovation Engineering and Science Research, 2(1): 1-9.

Hong, Y., Chan, D.W.M., Chan, A.P.C., Yeung, J.F.Y.2012. Critical Analysis of Partnering Research Trend in Construction, Journals. J. Manag. Eng., 28: 82-95.

Hosseini, M.R., Maghrebi, M., Akbarnezhad, A., Martek, I., Arashpour, M. 2018. Analysis of Citation Networks in Building Information Modelling Research. Journal of Constr. Eng. Manag.144(8): 1- 13. 
Hu, Z., Zhang, J., Lu, X. 2010. Development of a sub building information model for 4D structural safety analysis during construction, Proceedings of the International Conference on Computing in Civil and Building Engineering (ICCCBE 2010). Nottingham, UK.

Hwang, S., and Liu, L.Y. 2011. Radio frequency technology incorporated approaches to equipment collisions on jobsites. In Proceedings of the 28th International Symposium on Automation and Robotics in Construction, Seoul, Korea, 29 June-2 July 2011, 391-396.

Institute of Management 2018. World digital competitiveness ranking [accessed 2020 July 15] www.imd.org/wcc/world-competitiveness-center-rankings/worlddigital-competitiveness-rankings-2018/

Jin, R., Zou, P.X., Piroozfar, P., Wood, H., Yang, Y., Yan, L. and Han, Y. 2019. A science mapping approach-based review of construction safety research. Safety Sci. 113: $285-297$.

Jing, Q., Vasilakos, A. Wan, J., Lu, J. and Qiu, D. 2014. Security of the Internet of Things: Perspectives and challenges, Wireless Networks, 20:2481-2501.

Jung, K., Chu, B., Hong. 2013. Robot-based construction automation: An application to steel beam assembly (part ii), Automation in Construction, 32:62-79.

Kang, C., Wang, X. 2013.Special Issue on the Applications of Augmented Reality in Architecture, Engineering, and Construction, Automation in Construction, 33:12.

Khanzadi, M., Sheikhkhoshkar, M., Banihashemi, S. 2020. BIM applications toward key performance indicators of construction projects in Iran, International Journal of Construction Management, 20(4):305-320.

Kim, S.; Shin, D.H.; Woo, S. 2014.Identification of IT application areas and potential solutions for perception enhancement to improve construction safety. KSCE J. Civ. Eng., 18:365-379.

Kim, D.I., Cho, H. 2010. Safety and productivity analysis on alternative steel columngirder joint for automated construction, in Proceedings of International Conference on Control, Automation and Systems (ICCAS 2010) Seoul.

Kim, H.., Ahn, H. 2011. Temporary facility planning of a construction project using BIM (Building Information Modeling), Proceedings of the 2011 ASCE International Workshop on Computing in Civil Engineering. Miami, FL. 
Ku, K., Mills, T. 2010. Research needs for Building Information Modelling for Construction Safety, International Proceedings of Associated Schools of Construction 45th Annual Conference, Boston, MA.

Kyodo 2015. Panasonic to sell robot suits starting in September (2015). http://www.japantimes.co.jp/ news/2015/07/03/business/tech/panasonic-sellrobot-suits-september/. Accessed 10 April 2019.

Lee, H.S., Cho, M.W and Yang, H.M. 2014. Curing Management of Early-age Concrete at Construction Site using Integrated Wireless Sensors. J. Adv. Concr. Technol., 12: $91-100$.

Li, R. Y. 2018. An Economic Analysis on Automated Construction Safety, Springer Nature Singapore Pte Ltd.

Li, R. Y., Leung, T. 2017. Leading safety indicators and automated tools in the construction industry, 34th International Symposium on Automation and Robotics in Construction.

Li, R.Y. 2015. Generation x and y's demand for homeownership in Hong Kong, Pacific Rim Real Estate Journal, 21: 15-36.

Li, R.Y.M., Ng, P.L 2017. Wearable robotics and construction workers safety and health. In: 8th International Conference on Applied Human Factors and Ergonomics, Los Angeles.

Li, Y., Lai, H., Chen, C. 2017. A Scientometric Review of the Current Status and Emerging Trends in Project-Based Learning, International Journal of Information and Education Technology, 7(8): - 584.

Liang, H., Zhang, S., Su, Y. 2018. The structure and emerging trends of construction safety management research: a bibliometric review, International Journal of Occupational Safety and Ergonomic, 1: 20 - 29.

Lin,Y., Su,Y., Lo,N., Cheung,W., Chen, Y. 2013. Application of Mobile RFID-Based Safety Inspection Management at Construction Jobsite, Radio Frequency Identification from System to Applications, Mamun Bin Ibne Reaz, IntechOpen.

Lu, Y., Wub, Z., Changa, R. and Lib, Y. 2017. Building Information Modeling (BIM) for green buildings: A critical review and future directions, Automation in Construction, 83: $134-148$.

Luo, D., Ibrahim, Z. and Ismail, Z.2013. Optimization of the Geometries of Biconical Tapered Fiber Sensors for Monitoring the Early-Age Curing Temperatures of Concrete Specimens. Comput-Aided. Civ. Inf., 28:531-541. 
Luo, X., Li, H., Huang, T., Rose, T., 2016. A field experiment of workers' responses to proximity warnings of static safety hazards on construction sites. Safety Science 84: 216-224.

Maas G. and Van Gassel F.2005. The influence of automation and robotics on the performance construction. Automation in Construction, 14(4):435-441

Martínez-Aires, M.D., López-Alonso, M., Martínez-Rojas, M., 2018. Building information modelling and safety management: a systematic review. Safety Sci. $101,11-18$.

Melzner, J., Zhang, S., Teizer, J., Bargstädt, H.-J., 2013. A case study on automated safety

compliance checking to assist fall protection design and planning in building information models. Construction Management and Economics 31: 661-674.

Neto,D., Cruz,C.O., Rodrigues, F. 2016. Bibliometric analysis of PPP and PFI literature: overview of 25 years of research. J Const Eng M., 142(10).

Ni, Y.Q.; Xia, Y.X.; Ye, X.W. 2012. Structural Health Monitoring of a Tall Building with Huge Floating Platform. In Proceedings of the 4th International Conference on Smart Materials, Structures and Systems, Montecatini Terme, Italy, 10-14 June 2012.

Niu, Y., Lu, W., Liu, D. 2017. The application scenarios of smart construction objects (SCOs) in Construction, Proceedings of the 20th International Symposium on Advancement of Construction Management and Real Estate, 969-980.

Oesterreich, T.D., Teuteberg, F. 2016. Understanding the implications of digitization and automation in the context of industry 4.0: A triangulation approach and elements of a research agenda for construction industry, Computers in industry, 83: 121-139.

Olawumi, T.O., Chan, D.W.M., Wong, J.K.W., 2017. Evolution in the Intellectual Structure of BIM Research: A Bibliometric Analysis. Journal of Civil Engineering and Management, 23:1060-1081.

Olawumi, T. O., Chan, D. W. M. 2018. A Scientometric Review of Global Research on Sustainability and Sustainable Development. Journal of Cleaner Production, 183: 231-250.

Papayianni, I., Pachta, V. 2016. Evolution of Building Materials and Philosophy in Construction: A Process of Digitalization and Visualization of the Accumulated Knowledge. EuroMed. 
Patrucco, M., Bursano, D., Cigna, C., Fissore, F. 2010. Computer image generation for job simulation: an effective approach to occupational risk analysis, Safety Science, 48: 508-516.

Pritchard A. Statistical bibliography or bibliometrics? 1969. J Doc., 2: 348-349.

Ruggiero, A., Salvo, S., St. Laurent, C. 2016. Robotics in Construction, University of Worcester, Unpublished BSC Thesis.

Soungho, C. and Tomohiro, Y. 2010. Application of RFID technology to prevention of collision accident with heavy equipment. Automat. Constr., 19: 368-374.

Song, J., Zhang, H. and Dong, W.2016. A review of emerging trends in global PPP research: Analysis and visualization. Scientometrics, 107: 1111-1147.

Sekiya, H., Kinomoto, T. and Miki, C.2016. Determination Method of Bridge Rotation Angle Response Using MEMS IMU. Sensors, 16: 1882.

Su, H.-N., Lee, P.-C., 2010. Mapping knowledge structure by keyword co-occurrence: a first look at journal papers in Technology Foresight. Scientometrics 85 (1): 6579.

Suermann, P. 2009. Evaluating industry perceptions of building information modelling (BIM) impact on construction, International Journal of IT in Construction, 14: 574-594.

Sung, Y.C.; Lin, T.K.; Chiu, Y.T. 2016. A bridge safety monitoring system for prestressed composite box-girder bridges with corrugated steel webs based on in-situ loading experiments and a long-term monitoring database. Eng. Struct., 126: $571-585$.

Tang, S.L., Lee, H.K., Wong, K. 1997. Safety cost optimization of building projects in Hong Kong, Construction Management and Economics, 15:177-186.

Tang,W.L. and Yan, L.P. 2013 Research of WSN-based safety monitoring system for middle-and-small sized dams. Int. J. Digital Content Tech.

Teizer, J., Allread, B.S., Fullerton, C.E., Hinze, J., 2010. Autonomous pro-active realtime construction worker and equipment operator proximity safety alert system. Automation in Construction 19: 630-640.

Teizer, J. 2015. Wearable, Wireless Identification Sensing Platform: Self-Monitoring Alert and Reporting Technology for Hazard Avoidance and Training (SmartHat), Journal of Information Technology in Construction, 20: 295 -312. 
Teizer, J., Caldas, C.H., Haas, C.T. 2007. Real-Time Three-Dimensional Occupancy Grid Modeling for the Detection and Tracking of Construction Resources. ASCE Journal of Construction Engineering and Management, 133:880-888.

Toh, Y.Z., Goh, Y.M., Guo, B.H., 2016. Knowledge, Attitude, and Practice of Design for Safety:Multiple Stakeholders in the Singapore Construction Industry. Journal of Construction Engineering and Management, 04016131.

Van Eck, N.J.; Waltman, L. 2010. Software survey: VOSviewer, a computer program for bibliometric mapping, Scientometrics, 84: 523-538.

Van Eck, N.J., Waltman, L. 2014. Visualizing bibliometric networks. In Y. Ding, R. Rousseau, \& D. Wolfram (Eds.), Measuring scholarly impact: Methods and practice, $285-320$.

Van Eck, N. J.,Waltman, L. 2017. Citation-based clustering of publications using CitNet Explorer and VOSviewer, Scientometrics, 111:1053-1070.

Vatsal, V., Hoffman, G. 2017. Wearing your Arm on a Sleeve: Studying Usage Contexts for a Wearable Robotic Forearm, 26th IEEE International Symposium on Robot and Human Interactive Communication (RO-MAN) Lisbon, Portugal, $974-980$.

Vigneshkumar C and Urmi Ravindra Salve 2020. A scientometric analysis and review of fall from height research in construction. Construction Economics and Building, 20:1, 17-35

Vuksic,V.B., Invansic,L., Vugec, D.S. 2018. A preliminary literature review on digital transformation case studies. Conference Proceedings, Rome Italy, 20 (9) Part VIII, 952-957.

Wang, Y.H., Luo, J., Zhang, C.C. 2010. Design of safety-risk-management information system for urban rail transit construction based on GIS, Journal of Transportation Systems Engineering, and Information Technology, 10: 33-7.

Wang, J., Razavi, S. 2016. Two 4D Models Effective in Reducing False Alarms for Struck-by-Equipment Hazard Prevention. J. Comput. Civ. Eng., 30: 6.

Watson, A. 2010. BIM - driver for change, Proceedings of the International Conference on Computing in Civil and Building Engineering, ICCBE 2010, Nottingham.

Welch, L., Russell, D., Weinstock. D., Betit, E. (2015). Best Practices for Health and Safety Technology Transfer in Construction, American Journal of Industrial Medicine, 58: 849-857. 
Wu, W.W.; Yang, H.J.; David, A. 2010. Towards an autonomous real-time tracking system of near-miss accidents on construction sites. Automat. Constr., 19:134141.

Wuni, I.Y., Shen, G.Q.P. and Osei-Kyei, R.2019. Scientometric review of global research trends on green buildings in construction journals from 1992 to 2018. Energy Build., 190: 69-85.

Yang, R.J., Gunarathna, C., McDermott, V., Lingard, H., Zhao, H. and Liu, C. 2018. Opportunities for improving construction health and safety using real-time H\&S management Innovations : A socio-technical-economic perspective, International Journal of Construction Management, DOI: $10.1080 / 15623599.2018 .1490866$

Yin, S.Y.L., Tserng, H.P., Wang, J.C., Tsai, S.C. 2009. Developing a precast production management system using RFID technology, Automation in Construction, 18: 677-691.

Yu H. 2009. A knowledge-based system for construction health and safety competence assessment. University of Wolverhampton. United Kingdom.

Yu, S.Y., Wu, X.B. and Chen, G.H. 2015. Wireless sensor networks for bridge structural health monitoring. J. Softw., 26: 1486-1498.

Yusoff, M., Samin, R., Ibrahim, B. 2012. Wireless Mobile Robotic Arm, Procedia Engineering, 41: 1072-1078.

Zhang, J.; Zhou, J.K.; Ding, N. 2013. Study on variation of early temperature field and strain of long side wall concrete in the basement based on field monitoring and numerical analysis. Concrete, 11, 37-42.

Zhang, S., Sulankivi, K., Kiviniemi, M., Romo, I., Eastman, C.M., Teizer, J., 2015. BIM-based fall hazard identification and prevention in construction safety planning. Safety Science, 72: 31-45.

Zhang, S., Teizer, J., Lee, J.-K., Eastman, C.M., Venugopal, M., 2013. Building information modeling (BIM) and safety: Automatic safety checking of construction models and schedules. Automation in Construction 29: 183-195.

Zhang, M., Cao, T. and Zhao, X. 2017. Applying Sensor-Based Technology to Improve Construction Safety Management, Sensors, 17:1-24.

Zheng, X., Le, Y., Chan, A.P.C., Hu, Y., Li, Y. 2016. Review of the application of social network analysis (SNA) in construction project management research", International Journal of Project Management, 34(7):1214-1225. 
Zhong, D.X., Lv, H.Q. and Han, J.Q. 2014. A Practical Application Combining Wireless Sensor Networks and Internet of Things: Safety Management System for Tower Crane Groups. Sensors, 14: 13794-13814.

Zhou, N., Ding, L.Y., Chen, L.Y. 2013.Application of 4D visualization technology for safety management in metro construction, Automation in Construction, 34: 2536.

Zhou, W., Whyte, J., Sacks, R. 2012. Construction safety and digital design: A review, Automation in Construction, 22: 102-111.

Zhou, Z., Irizarry, J., Li, Q. 2013. Applying advanced technology to improve safety management in the construction industry: a literature review, Construction Management and Economics, 31: 606-622.

Zolfagharian, S., Irizarry, J., Ressang, A., Nourbakhsh, M., Gheisari, M. 2014. Automated safety planning approach for residential construction sites in Malaysia, International Journal of Construction Management, 14(3): 134-147

Table 1. Most cited publication sources

Table 2. Number of publications per author

Table 3. Most active keywords of publications on digital technologies

Figure 1. Outline of research design

Figure 2. Literature search and indexing strategy

Figure 3. Annual Publication Distribution

Figure 4. Publication source type

Figure 5. Publication Country/ region distribution

Figure 6. Overlay visualization co-authorship network 
Figure 7. Cluster Visualization Map for co-occurring keywords

Figure 8. Overlaying visualization network of research topics 
Figure 1: Outline of research design

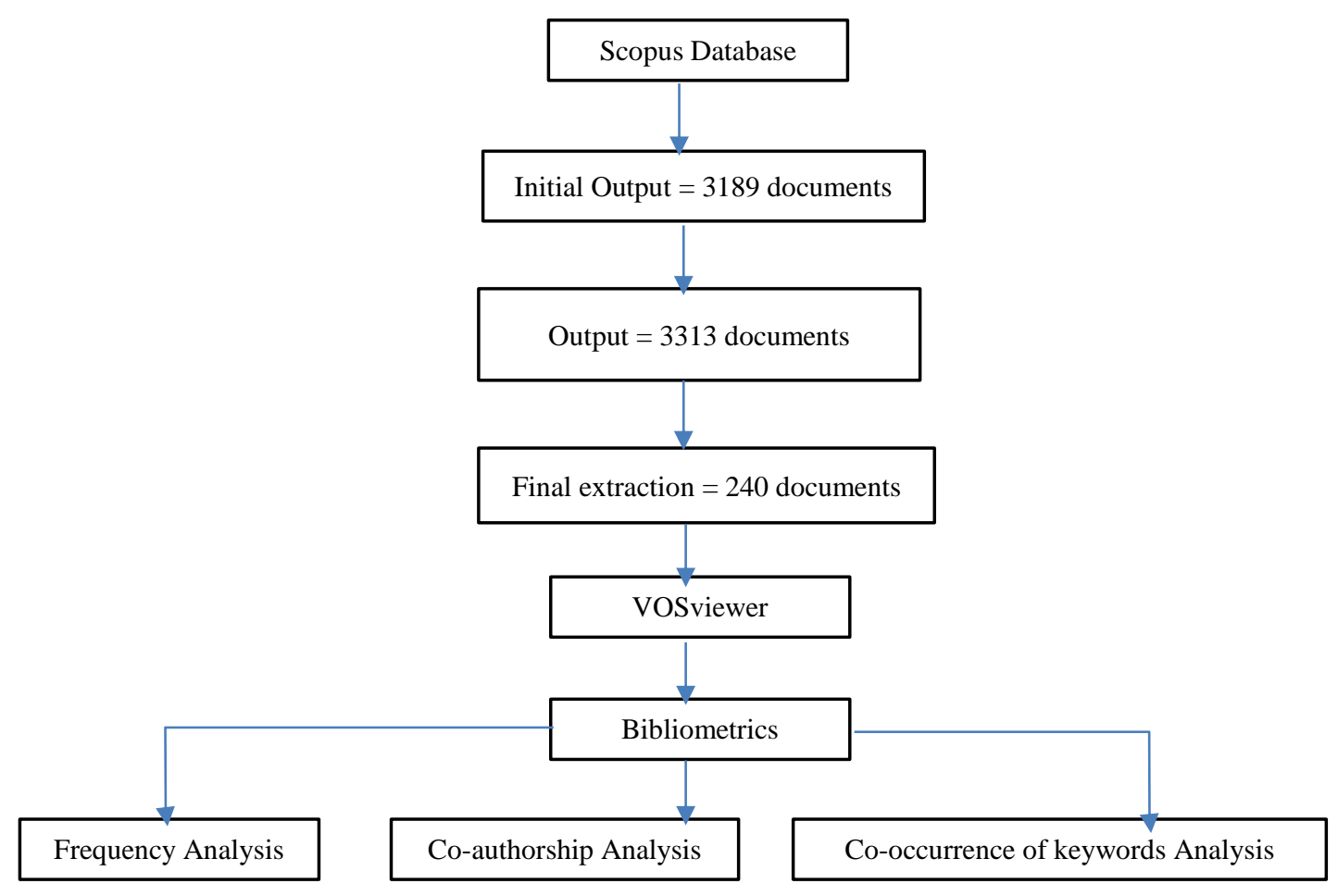


Figure 2: Literature search and indexing strategy

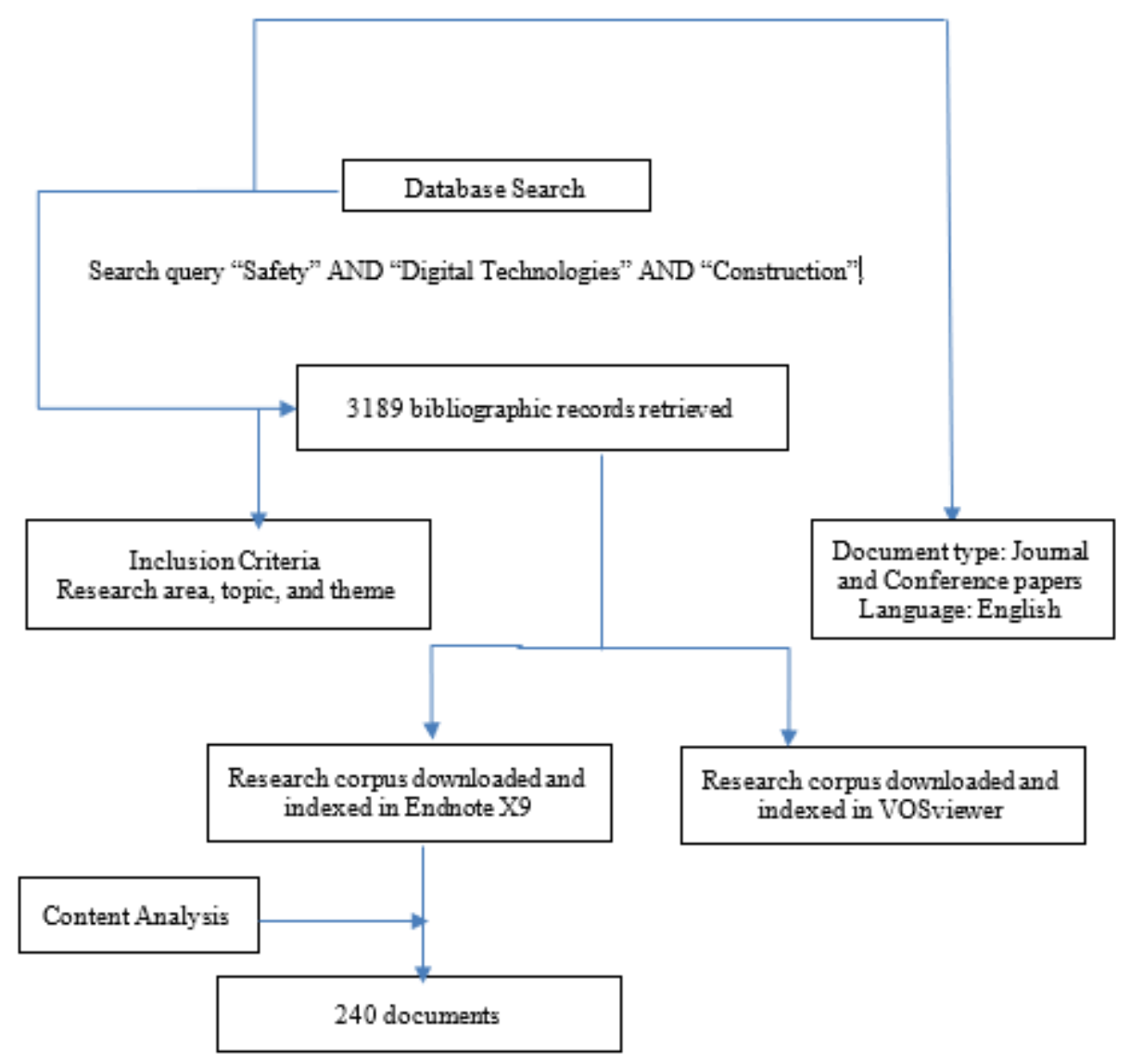

Figure 3: Annual Publication Distribution

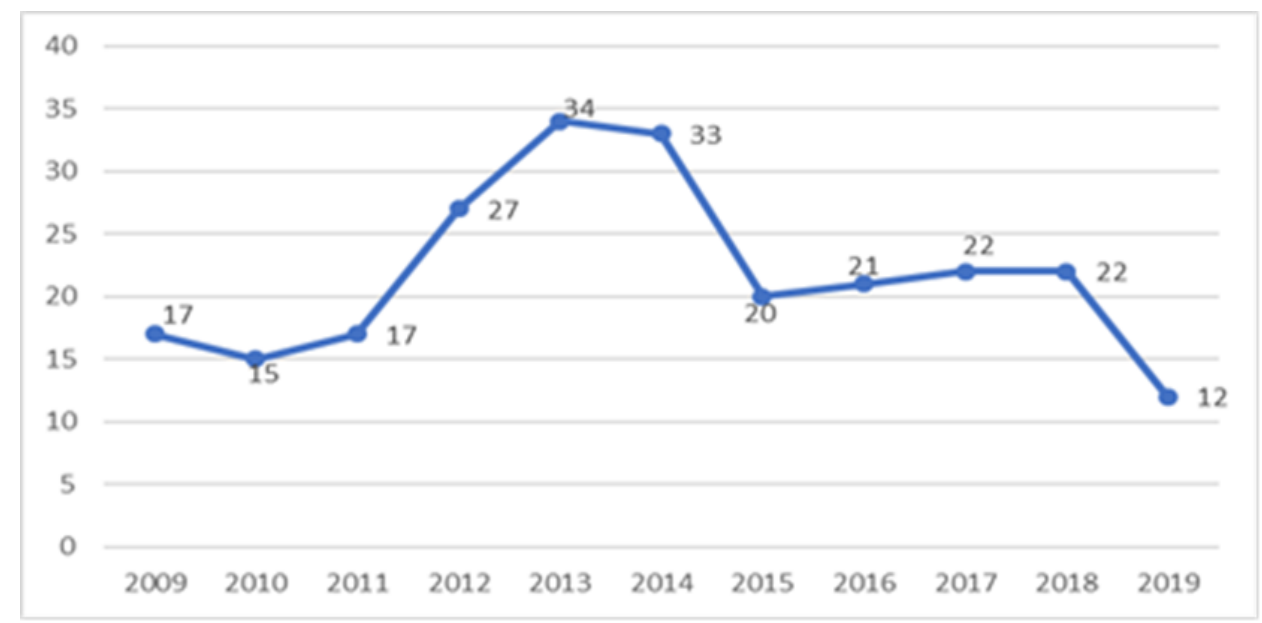


Figure 4: Publication source type

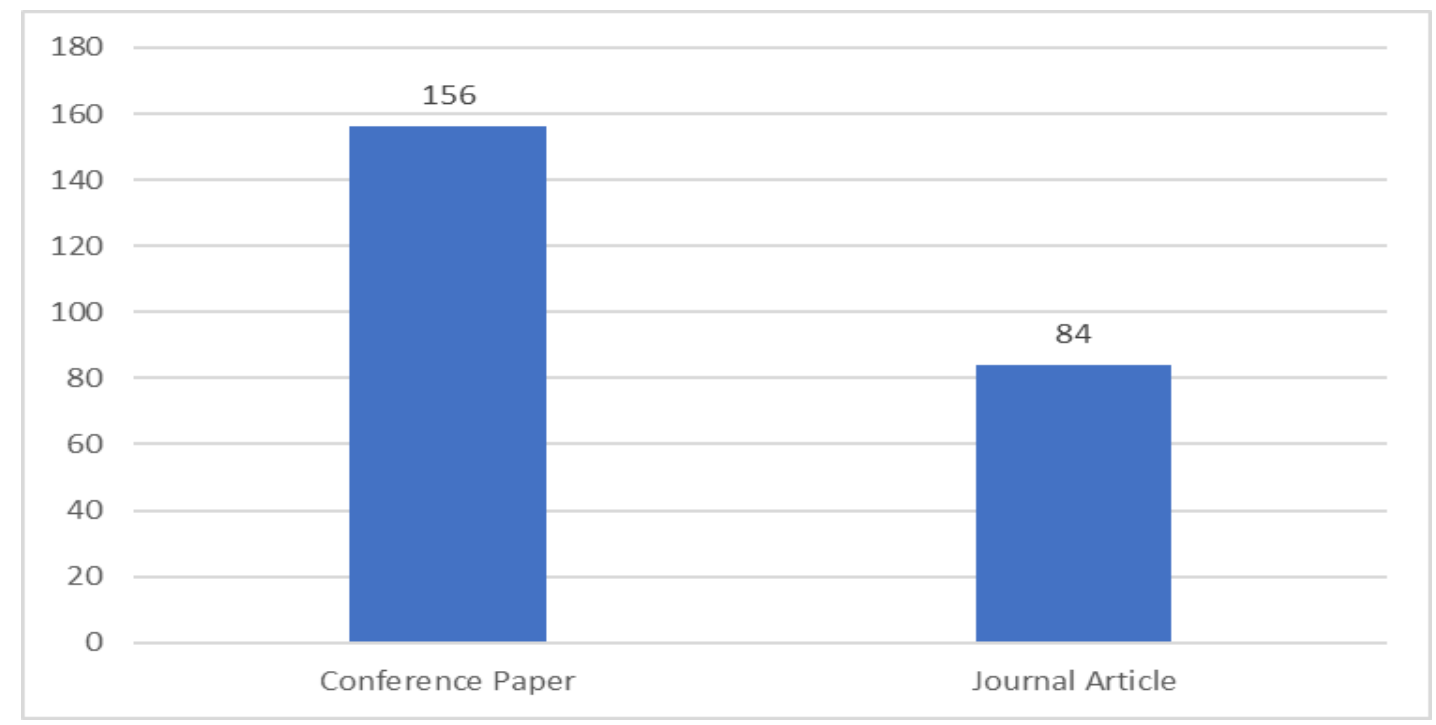

Figure 5: Publication Country/ region distribution

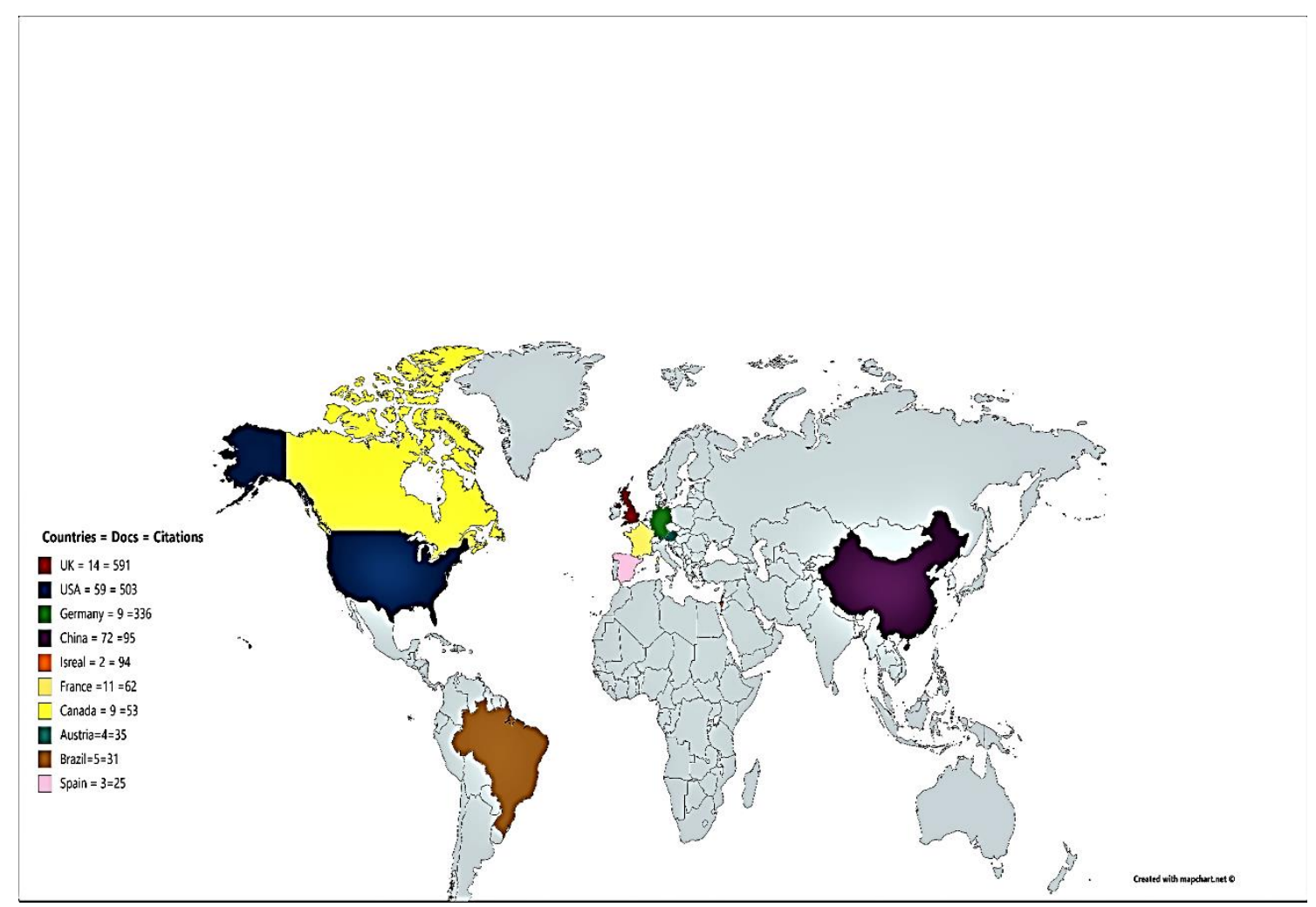


Figure 6: Overlay visualization co-authorship network
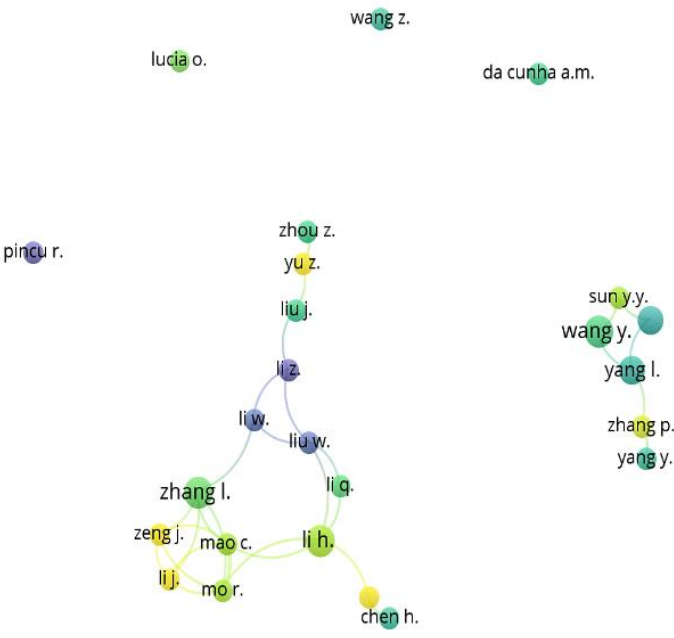

xus.

象 VoSviewer

zhang w.

\begin{tabular}{|lll}
\hline 2010 & 2012 & 2014 \\
\end{tabular}

Figure 7: Cluster Visualization Map for co-occurring keywords

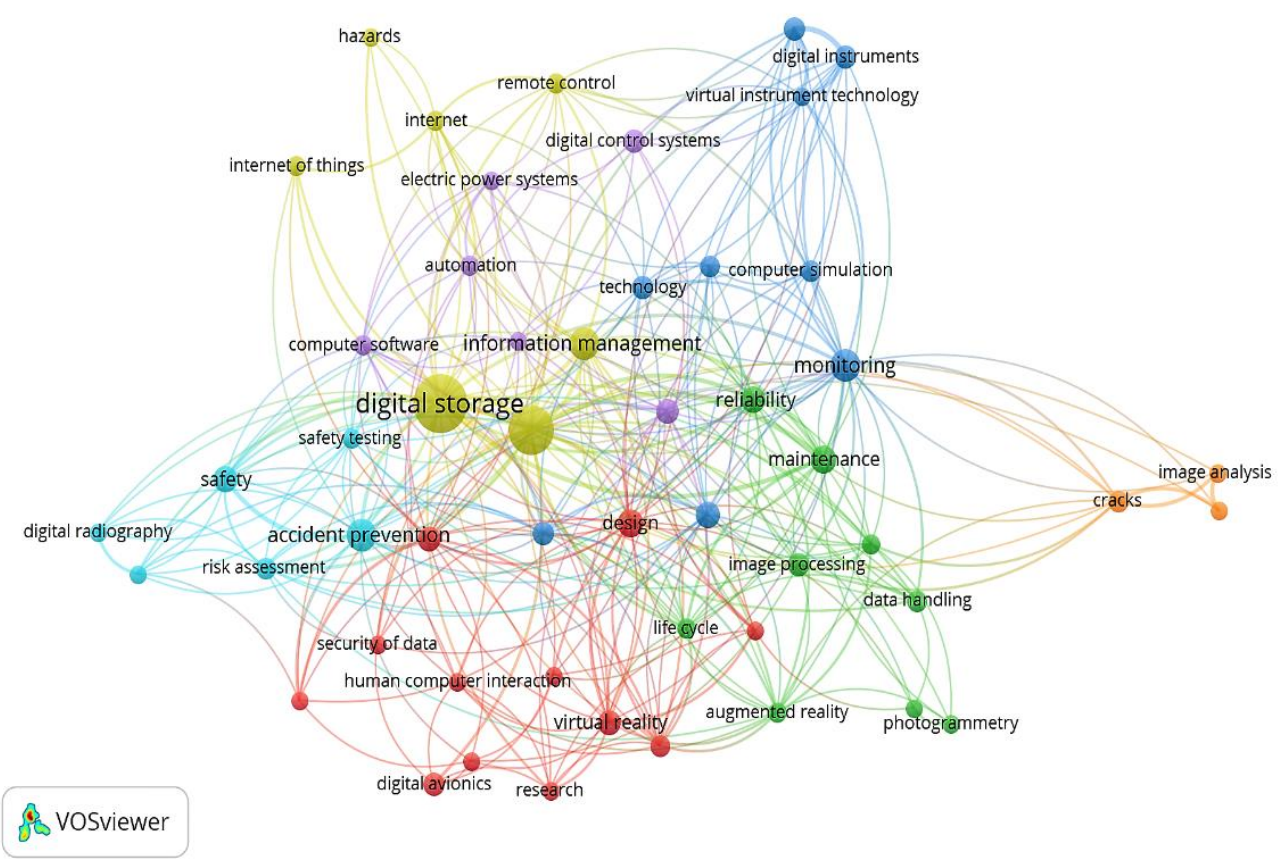


Figure 8: Overlaying visualization network of research topics

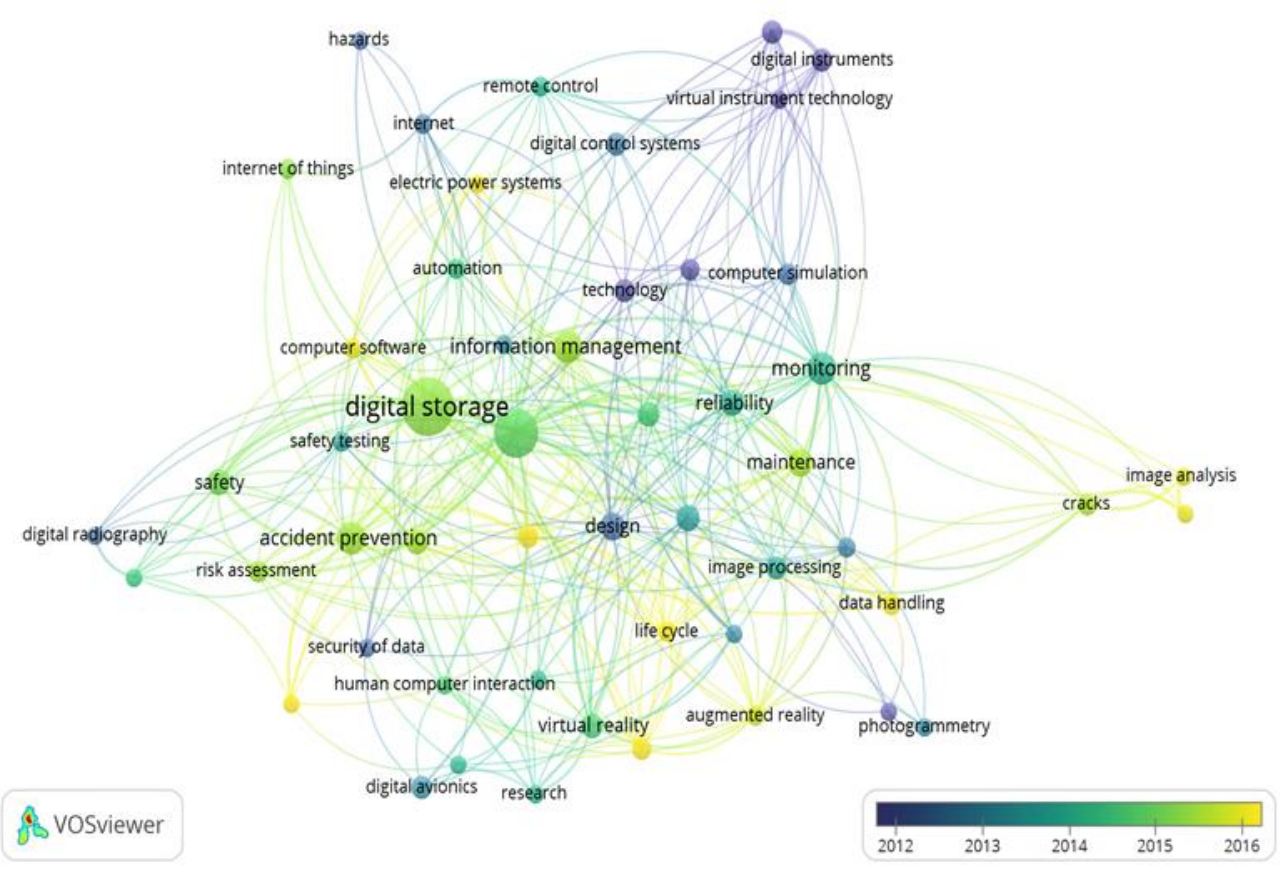


Table 1: Most cited publication sources

\begin{tabular}{llcc}
\hline No. & Source & Citations & Documents \\
\hline 1 & Automation in Construction & 446 & 3 \\
\hline 2 & IEE transactions on industrial electronics & 93 & 2 \\
\hline 3 & Proceedings of the IEE & 47 & 2 \\
\hline 4 & $\begin{array}{l}\text { Digest of papers- IEE radio frequency integrated circuits radio } \\
\text { frequency }\end{array}$ & 34 & 2 \\
& AIAA/IEEE digital avionics systems conference & 16 & 8 \\
\hline 5 & International Journal of Civil Engineering & 13 & 2 \\
\hline 7 & 2011 International Conference on Electrical and Control & 13 & 2 \\
\hline 8 & Engineering, ICECE 2011 - Proceedings & & 15 \\
\hline 9 & Advanced material research & 10 & 4 \\
\hline 10 & Lecture notes in electrical engineering & 8 & 5 \\
\hline
\end{tabular}


Table 2: Number of publications per author

\begin{tabular}{|c|c|c|c|c|}
\hline & Authors & Affiliation & Documents & Citations \\
\hline 1 & Mao, C. & $\begin{array}{l}\text { Huazhong University of Science and } \\
\text { Technology, Wuhan, China }\end{array}$ & 2 & 7 \\
\hline 2 & Mo, R. & $\begin{array}{l}\text { Huazhong University of Science and } \\
\text { Technology, Wuhan, China }\end{array}$ & 2 & 7 \\
\hline 3 & $\mathrm{Li}, \mathrm{H}$. & $\begin{array}{l}\text { Beijing Satellite Manufacturing Factory, } \\
\text { Beijing, 100096, China }\end{array}$ & 4 & 2 \\
\hline 4 & Zhang, L. & XuZhou Normal University of China & 4 & 8 \\
\hline 5 & $\mathrm{Li}, \mathrm{J}$. & $\begin{array}{l}\text { Zhejiang Business Technology Institute, } \\
\text { Ningbo, China }\end{array}$ & 2 & 6 \\
\hline 6 & Liu,W. & $\begin{array}{l}\text { Hebei Chemical and Pharmaceutical } \\
\text { College, Shijiazhuang, China }\end{array}$ & 2 & 1 \\
\hline 7 & Zeng, J. & $\begin{array}{l}\text { Guangdong Province Key Laboratory of } \\
\text { Smart Grid Technology, Guangzhou, China }\end{array}$ & 2 & 6 \\
\hline 8 & $\mathrm{Li}, \mathrm{W}$. & $\begin{array}{l}\text { Shandong University of Technology, Zibo, } \\
\text { China }\end{array}$ & 2 & 3 \\
\hline 9 & $\mathrm{Li}, \mathrm{Z}$. & $\begin{array}{l}\text { Shandong University of Technology, Zibo, } \\
\text { China }\end{array}$ & 2 & 3 \\
\hline 10 & Yang, L. & $\begin{array}{l}\text { Northwest A and F University, Shaanxi, } \\
\text { China }\end{array}$ & 3 & 12 \\
\hline 11 & $\mathrm{Li}, \mathrm{Q}$. & $\begin{array}{l}\text { Shijiazhuang Information Engineering } \\
\text { Vocational College, Shijiazhuang, China }\end{array}$ & 2 & 1 \\
\hline 12 & $L i, Y$. & $\begin{array}{l}\text { Beijing Satellite Manufacturing Factory, } \\
\text { Beijing, China }\end{array}$ & 2 & 2 \\
\hline 13 & Liu, J. & Sichuan University, Chengdu, China & 2 & 2 \\
\hline 14 & Sun, Y.Y. & $\begin{array}{l}\text { China University of Mining and Technology } \\
\text { (Beijing), Beijing, China }\end{array}$ & 2 & 2 \\
\hline 15 & Wang, Y. & $\begin{array}{l}\text { South China University of Technology, } \\
\text { Guangzhou, Guangdong, China }\end{array}$ & 4 & 3 \\
\hline 16 & Yang, F. & $\begin{array}{l}\text { Northwest A and F University, Shaanxi, } \\
\text { China }\end{array}$ & 3 & 2 \\
\hline 17 & Yu, Z. & $\begin{array}{l}\text { Beijing Construction Engineering Group, } \\
\text { Beijing, China }\end{array}$ & 2 & 1 \\
\hline 18 & Zhang, $\mathrm{P}$. & Hohai University, Nanjing, China & 2 & 10 \\
\hline 19 & Chen, $\mathrm{H}$. & $\begin{array}{l}\text { China University of Technology, Taipei, } \\
\text { Taiwan }\end{array}$ & 2 & 2 \\
\hline 20 & Yang, Y. & Northeastern University, Shenyang, China & 2 & 3 \\
\hline 21 & Zhou, Z. & University of Melbourne, Parkville, Australia & 2 & 3 \\
\hline 22 & $\begin{array}{l}\text { Da Cunha, } \\
\text { A. M. }\end{array}$ & $\begin{array}{l}\text { Instituto Tecnologico de Aeronautica, Sao } \\
\text { Jose Dos Campos, Sao Paulo, Brazil }\end{array}$ & 2 & 1 \\
\hline 23 & Lucia, O. & University of Zaragoza, Zaragoza, Spain & 2 & 18 \\
\hline 24 & Pincu, $\mathrm{R}$. & Vidisco Limited, Isreal & 2 & 3 \\
\hline 25 & Wang, Z. & GSE Systems, Sykesville, United States & 2 & 1 \\
\hline 26 & Xu, S. & $\begin{array}{l}\text { Wuhan University of Science and } \\
\text { Technology, Wuhan, China, }\end{array}$ & 2 & 1 \\
\hline 27 & Zhang, W. & Weifang University, Weifang, China & 3 & 12 \\
\hline
\end{tabular}


Table 3: Most active keywords of publications on digital technologies

\begin{tabular}{lcc}
\hline Keyword & Occurrences & Total Link \\
\hline Safety engineering & 35 & 82 \\
\hline Digital storage & 50 & 37 \\
\hline Accident prevention & 16 & 39 \\
\hline Monitoring & 16 & 24 \\
\hline Information technology & 10 & 21 \\
\hline Risk assessment & 7 & 19 \\
\hline Cracks & 7 & 8 \\
\hline Digital avionics & 8 & 16 \\
\hline Safety testing & 6 & 14 \\
\hline Automation & 6 & \\
\hline
\end{tabular}

